\title{
RED-TAILED HAWK CAPTURED IN A SHARP-TAILED GROUSE TRAP
}

RICHARD K. BAYDACK, Natural Resources Institute, University of Manitoba, Winnipeg, Manitoba. R3T 2N2

During a 3-year study on Sharp-tailed the cage-like traps, with two dead SharpGrouse in the Carberry Sand Hills, grouse were trapped on dancing grounds during early mornings. ${ }^{1}$ On 15 May 1984 a live, juvenile Red-tailed Hawk was in one of tailed Grouse. Sunrise was at approximately $0545 \mathrm{~h}$, temperature was $0^{\circ} \mathrm{C}$, and wind was negligible from the northwest.

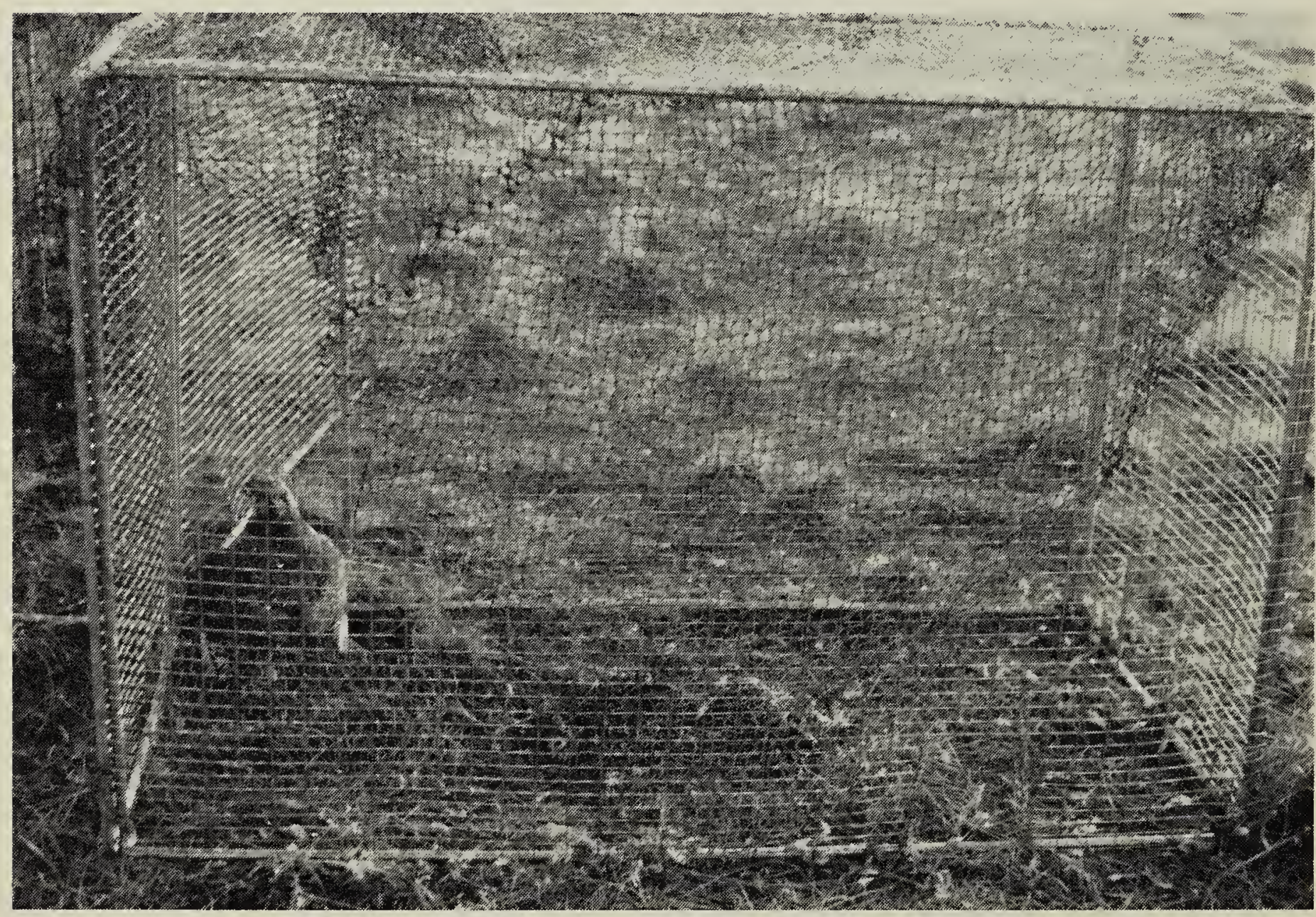

Figure 1. Red-tailed Hawk in Sharp-tailed Grouse trap. Two dead grouse at center of trap.

R.K. Baydack 
Grouse were live-trapped on leks, banded, and released during March - May 1983 - 1985 using two rectangular $1.8 \times 3.7-\mathrm{m}$ traps per $\{$ ek. Traps were constructed of aluminum conduit frames $(1.25-\mathrm{cm} \mathrm{dia.})$, welded wire mesh sides $(5.1 \times 2.5 \mathrm{~cm})$, and nylon mesh tops $(2.5 \times 2.5 \mathrm{~cm})$. Each side panel $(1.2 \times 0.9$ or $1.8 \mathrm{~m})$ had a 25 $\times 15-\mathrm{cm}$ opening with an inverted, woven wire funnel. Trapping occurred typically for a maximum of 3 mornings and evenings per lek. The hawk was captured on the first morning of trapping at this site.

The trap was designed to allow stooping or crouching sharptails in through a funnel entrance, but they were not able to escape if standing erect. The hawk had no other means of entry to the trap, and presumably also squeezed through the funnel.

At $0500 \mathrm{~h}$ there was no activity on the dancing ground. Thirty minutes later the hawik and two dead grouse (adult male and adult female) were in one trap and a live adult male Sharp-tailed Grouse was in the other trap. Seven more grouse flushed from the periphery of the lek.

The hawk attempted to escape and battered into the cage walls. It's back feathers appeared brown-streaked and the tail graybrown. Identification as a juvenile Redtailed Hawk was later verified by observers S.P. McGovern and M.E. Stoll, who were assisting me. Figure 1 is a photograph of the scene in the early morning light.

The trap was lifted to allow the hawk to scurry out. It flew off to perch for about 10 minutes in a 10-m tall aspen approximately $500 \mathrm{~m}$ distant. The Red-tailed Hawk then departed, but was on a fencepost within $50 \mathrm{~m}$ of the trap at 0745 h. The trap was moved elsewhere to avoid further predation. On several subsequent mornings the hawk was seen flying near the dancing ground; Sharp-tailed Grouse continued to display there but no further evidence of raptor predation was found. No encounters with raptors occurred at other Sharp-tailed Grouse leks.

Owing to their relatively large size and slow speed, Red-tailed Hawks are not effective predators on dancing Sharp-tailed Grouse. ${ }^{2}{ }^{4}$ The hawk in the trap would be at an obvious advantage over the confined grouse. The peculiar behaviour of this hawk to obtain prey might be due to its immaturity. The hawk may have keyed in to the oddity of its prey being unable to escape attack. ${ }^{3}$ In either case, early morning hunting by Red-tailed Hawks at sharptail dancing grounds is not common. ${ }^{2}$ Continued observations of the hawk at this lek suggests that lek locations can be learned more easily by predators if obvious visible cues such as the trap are available.

\section{Acknowledgments}

Special thanks to S.P. McGovern and M.E. Stoll for their assistance. Support and funding for the project were provided by the Natural Resources Institute at the University of Manitoba, the Manitoba Department of Natural Resources, the Natural Sciences and Engineering Research Council of Canada, and the Canada Department of National Defence.

'BAYDACK, R.K. 1986. Sharp-tailed grouse response to lek disturbance in the Carberry Sand Hills of Manitoba. Ph. D. Thesis. Colorado State Univ., Fort Collins. 83 pp.

2 BERGER, D.D., F. HAMERSTROM, and F.N. HAMERSTROM, Jr. 1963. The effect of raptors on prairie chickens on booming grounds. J. Wildl. Mgmt. 27:778-791.

${ }^{3}$ MARKS, J.S., and V.S. MARKS 1987. Influence of radio collars on survival of Sharptailed Grouse. J. Wildl. Mgmt. 51:468:471.

4 SCHWARTZ, C.W. 1945. The ecology of the prairie chicken in Missouri. University of Missouri Studies 20:1-99. 